\title{
ARTIGO
}

\section{Concursos públicos de policiais}

\section{militares: tatuagem como fator de exclusão injustificada}

Lorena Martoni de Freitas $^{1} \mid$ Lucas de Souza Prates $^{2}$

Como citar este artigo: MARTONI DE FREITAS, Lorena; PRATES, Lucas de Souza. Concursos públicos de policiais militares: tatuagem como fator de exclusão injustificada. Revista de Ciências do Estado. Belo Horizonte: v. 5, n. 1, e14946. ISSN: 2525-8036.

Resumo: por meio de conceitos trabalhados por Pierre Bourdieu, principalmente de violência simbólica, capital simbólico e campo jurídico-estatal, buscou-se analisar o Recurso Extraordinário 898.540 de repercussão geral, verificando a existência de uma cláusula de barreira injustificada voltada à exclusão de candidatos com tatuagens em concursos públicos de Policiais Militares. Para isso, recortou-se historicamente o processo de estigma associado às tatuagens com o fim de contrapor esse elemento de contracultura à lógica do poder público, tendo em vista os princípios da impessoalidade, legalidade, moralidade do Direito Administrativo, buscando explicitar como esses podem não estar sendo observados, em alguma medida, por agentes e instituições do aparato estatal. Com isso, propõe-se um exercício crítico em relação ao Estado de Direito brasileiro.

Palavras-chave: violência simbólica; concursos públicos; campo jurídico; Direito Administrativo; tatuagens.

Recebido em 15.08.2019

Aprovado em 18.05.2020

Publicado em 02.06.2020

\section{INTRODUÇÃO}

Os concursos públicos, no contexto brasileiro, apresentam diversos cargos ofertados pelo Estado, o que permite o ingresso nos órgãos públicos nas variadas carreiras. Nesse

\footnotetext{
${ }^{1}$ Graduada (2014) e Mestra (2017) em Direito pela Faculdade de Direito e Ciências do Estado da Universidade Federal de Minas Gerais (UFMG). Doutoranda (2017-) em Direito com enfoque na área de Filosofia Política pelo programa de pós-graduação da Faculdade de Direito e Ciências do Estado da UFMG, com estágio de pesquisa de "Doutorado Sanduíche" no Programa de Filosofia da Université Paris 8 (França) entre setembro/2019 e fevereiro/2020.

${ }^{2}$ Graduando (2018-) em Direito pela Universidade Federal de Ouro Preto. Membro do Grupo de Estudos em Transições e Autoritarismo da Universidade Federal de Ouro Preto.
} 
contexto, razões atrativas para os indivíduos se tornarem agentes públicos se traduzem nas mais variadas formas: estabilidade, remuneração, processo de seleção mais objetivo, entre outros $^{3}$. Como apresenta Aline Santos, “estima-se que mais de 12 milhões de pessoas estavam se preparando para concursos públicos em 2013, fazendo movimentar um comércio que gira em torno de R $\$ 50$ bilhões e crescimento de cerca de 40\% ao ano.” (2014, p. 14). Com isso, vemos abrir uma nova segmentação de mercado de concursandos e concurseiros (SANTOS, 2014, p. 140).

Os cargos para policiais militares são abrangidos por essa lógica e, nesse contexto, deveriam visar à manifestação de candidatos heterogêneos, pois a pluralidade e diversidade, são fundamentos do Estado Democrático de Direito da República Federativa do Brasil (FERNANDES, 2017, p. 296). Afinal, “o concurso público, não somente deve ser vislumbrado por meio do pano de fundo do princípio democrático, mas se caracteriza como processo público para materializar a cidadania.” (OHLWEILER, 2018, p. 356).

Não obstante, a partir da decisão do Recurso Extraordinário 898.540 - São Paulo (RE. 898-540), julgado em agosto de 2016, encontramos uma dissonância entre essa premissa e a forma como o Estado e seus atores institucionais têm atuado excluindo alguns candidatos a cargos de policiais militares por serem tatuados, evidenciando uma clara reprodução de uma relação de poder no processo seletivo, nos termos daquilo que o sociólogo francês Pierre Bourdieu denominou como violência simbólica (BOURDIEU, 1989, p. 11). Isso porque, com tal exclusão, o Estado acaba por legitimar uma dominação de expressão de mundo discriminatória, corroborando certo juízo de valor acerca de negação uma parcela da sociedade ao impedi-la de participar da formação do poder público.

A partir dessa ideia, recorremos a uma narrativa acerca da prática ocidental da tatuagem a fim de entender o porquê dessa parcela da população apresentar determinado arquétipo no imaginário social (MORAES, 1997, p. 95), arquétipo esse que tem sido reproduzido e reforçado pelas instâncias do poder público através da negativa de oportunidades de ingresso nos cargos públicos. Nesse viés, foi imprescindível compreender como as tatuagens têm sido utilizadas no Brasil, bem como as motivações dos indivíduos em optarem por essa modificação corporal, dada a importância da análise sob uma perspectiva antropológica para compreensão do campo simbólico ao qual elas estão vinculadas, tendo como principal fonte de pesquisa as vivências relatadas nos trabalhos de Andrea Pérez e

\footnotetext{
${ }^{3}$ Existe a carência de sistematização científica sobre o assunto. A respeito das motivações dos candidatos, veja: ESTRATÉGIA CONCURSOS. Entrevistas. <https://www.estrategiaconcursos.com.br/blog/depoimentos/ entrevistas-texto/> Acesso em 19 de junho. 2019.
} 
Débora Leitão $(2004,2012)$. Todavia, ressalta-se a dificuldade para a pesquisa bibliográfica nesta parte, tendo sido necessário recorrer a diversos materiais pontuais para determinados períodos, dado que as publicações apresentavam grande rupturas históricas.

Em outra medida, as relações de poder no campo estatal, e a maneira como o Estado justifica sua soberania e sua impessoalidade, constituíram, também, o cerne desta análise crítica, realizada a partir de algumas das propostas do já citado autor Pierre Bourdieu, em seus livros "Poder simbólico" (1989) e "Sobre o Estado" (2012). Neles temos os conceitos de violência simbólica, poder simbólico e a maneira como o campo estatal é tangenciado pelas lutas de poder, por ter forte teor legitimador e universalista, principalmente por justificar suas medidas em prol do bem público, restando assim explicitado como os agentes do Estado apresentam elevado grau de capital político, definido como o reconhecimento positivo de suas ações na sociedade (BOURDIEU, 1989, p. 166). Ainda nesta linha, para adaptar a nuances dessas leituras para a realidade do Estado brasileiro, ponderou-se a argumentação apresentada no Supremo Tribunal Federal (STF) no Recurso Extraordinário 898.540, evidenciando e problematizando os dispositivos constitucionais a serem discutidos dentro do ordenamento jurídico.

A análise realizada a partir do marco teórico supracitado foi contrastada com os cânones do Direito Administrativo, com destaque para a obra de Celso Antônio Bandeira de Mello que, em seu livro "Curso de Direito Administrativo", retrata como a Administração Pública, e as pessoas que a exercem, devem operar visando ao interesse coletivo e seguindo princípios gerais do Direito (MELLO, 2009, p. 28). Além da complementação de outras fontes do direito administrativo como José dos Santos Carvalho Filho (2018), abordando os temas centrais sobre as responsabilidades dos agentes públicos e Maria Sylvia Zanella Di Pietro (2017) para reflexão crítica.

Sendo assim, foi analisada a construção argumentativa da decisão do Recurso Extraordinário 898.540 e de outros instrumentos normativos, a fim de se compreender o sistema de concursos em que os cidadãos candidatos aos editais de policiais militares, especialmente tatuados, estão submetidos.

Ainda que os desdobramentos dessa discussão possam seguir diferentes caminhos, ressalta-se que aqui o objetivo foi tensionar a lógica pública pretensamente objetiva do Estado face a inevitável subjetividade e visão de mundo de seus agentes no que tange à percepção acerca de tatuagens. 


\section{NARRATIVA SÓCIO-HISTÓRICA DAS TATUAGENS E SEUS PROCESSOS DE ESTIGMATIZAÇÃO}

As tatuagens, enquanto forma de exercício cultural de uso do corpo dentro do tempo e espaço, podem ser percebidas como processos de construções simbólicas que revelam uma complexidade psicossocial. Atualmente, é possível afirmar que elas têm sido adotadas cada vez mais pela população moderna ocidental por diversos motivos, como a estética, narrativas simbólicas, conquistas, cunho religioso, sendo consonante com sua herança histórica.

É possível perceber como marco inicial da narrativa ${ }^{4}$ histórica das tatuagens o contato dos navegadores europeus com os povos originários das Ilhas do Pacífico no século XVIII, especificamente o capitão britânico James Cook, que retornou com um homem nativo da Polinésia e repleto de tatuagens, conhecido como "Omai” (LEITÃO; ECKERT, 2004, p. 4). Assim, estabeleceu-se a divulgação da prática e o surgimento das primeiras telas humanas ocidentais, adotadas especialmente por marinheiros, navegantes e viajantes, que aderiram à ideia vista como "exótica". Trata-se de uma adoção diferente de prática comparada ao seu uso pelos povos originários do Mediterrâneo, que se tatuavam por motivos religiosos e de cunho místico; aos da África, onde as tatuagens representavam marcas sociais de viés estamental e religiosos; ou Havaí, no qual remetiam à transição do ciclo da vida ou à memória a algum ente querido (VILHENA; NOVAES; ROSA, 2015, p. 134); nos povos originários do Brasil as manifestações são diversas, cada povo utiliza técnicas específicas e percebem essas imagens como algo além do plano do simbolismo (LAGROU, 2011, p. 767), mediando o interior e exterior do corpo (LAGROU, 2011, p. 757).

Tal prática ficou restrita a esses pequenos grupos de seminômades pois as técnicas antigas utilizadas para a pigmentação consistiam em um trabalho artesanal longínquo, podendo demorar horas e dias. Porém, ela se ampliou no século XIX mediante a instauração da eletricidade e, com isso, o setor foi modernizado pela criação da máquina de tatuar por O’Reilly, em Nova York, 1891. Logo houve uma maior divulgação da prática pela facilitação do procedimento, emergindo, sobretudo, espaços físicos específicos para essas alterações corporais, transmissão dos conhecimentos, e sua mercantilização: venda de desenhos prontos para marcar a pele, maior demanda, maior profissionalismo.

Não obstante, seu "exotismo" se afirmava, dada a atratividade de pessoas com excessos de tatuagens no meio circense, no qual pessoas, famílias, casais tatuados, eram

\footnotetext{
${ }^{4}$ Destaca-se que o recorte para a narrativa aqui adotada para o entendimento desse fenômeno é uma das perspectivas possíveis, pois diversos outros moldes e eventos ao longo da história da humanidade podem ser percebidos de diferentes pontos de vistas ou de partida.
} 
exibidos como se fossem espetáculos, criando uma via de excentricidade perpetuada por muito tempo. Nesse contexto, a marginalização se intensifica uma vez que determinados grupos marginalizados - marinheiros, soldados, prostitutas, prisioneiros - eram as principais pessoas que compunham o universo da pigmentação. Por exemplo, Cesare Lombroso, criminologista italiano do século XX, considerava a tatuagem como objeto de identificação da criminalidade da pessoa, aproximando a característica com uma prova ou viés confirmatório da ligação do sujeito com o crime (VILHEN; ROSA; NOVAES, 2015, p. 136). Em sua obra "O homem delinquente", Lombroso tentou catalogar os traços e formas das tatuagens dos criminosos, então denominados "delinquentes", no intuito de verificar as causas e entendê-las a partir da relação com os crimes (LOMBROSO, 2007, p. 29). Dessa maneira, conclui haver a predisposição de tatuados para o crime: "O lugar da tatuagem, e sobretudo o número, são de grande importância antropológica, porque provam a vaidade instintiva que é característica no criminoso." (LOMBROSO, 2007, p. 35)

Paralelamente, os criminosos utilizavam as marcações corporais como forma de comunicação, aderindo a uma linguagem própria, transparecendo os crimes cometidos, suas hierarquias e posições, ou seja, um sistema comunicativo desenvolvido internamente (LEITÃO, 2004, p. 16). Assim, de forma consequente, aos rótulos da exoticidade e da marginalidade seria somado o da criminalidade.

Nessa mesma ótica, mais grupos desvinculados do padrão socialmente aceito, principalmente da ordem da contracultura, surgem no século XX: as ditas tribos urbanas hippies, punks, skinheads -, cuja estetização do corpo era vista como forma de protesto social, podendo reafirmar sua ruptura com protocolo social e regras convencionais. Dessa maneira, o imaginário coletivo, em consonância com a carga estigmatizante sócio-histórica adquirida, ligava as tatuagens com a anormalidade, impureza, sujeira. (PÉREZ, 2006, p. 184)

Junto a esses elementos de ordem antropológica, salienta-se ainda a forte presença da moralidade judaico-cristã na criação desses conceitos negativos:

Não façam cortes em seus corpos por causa dos mortos, nem tatuagem em si mesmos. Eu sou o Senhor. (LEVÍTICO, 19:28)

$$
\text { (...) }
$$

Acaso não sabem que o corpo de vocês é santuário do Espírito Santo que habita em vocês, que lhes foi dado por Deus, e que vocês não são de vocês mesmos? Vocês foram comprados por alto preço. Portanto, glorifiquem a Deus com o seu próprio corpo. (I CORÍNTIOS, 6:19-20)

Nesse campo religioso, as tatuagens foram ligadas à ideia de "profanação" contra o próprio corpo, supostamente semelhante à imagem de Deus, visto que seria um atentado à 
natureza humana. Esta concepção ainda é presente, apesar de ser flexibilizada em algumas vertentes da matriz religiosa judaico-cristã.

Esse cenário começa a mudar por volta de 1980, com as expressões midiáticas, atores, cantores e personagens apresentando pigmentação definitiva, o que veio acompanhado do crescimento de lojas especializadas no procedimento, técnicas e tecnologias aprimoradas, segmentando uma qualificação profissional mais ponderada. Igualmente, esses espaços físicos mudaram, uma vez que se preocupavam em passar maior credibilidade e biossegurança do local, por meio de um caráter clínico (RODRIGUEZ; CARRETEIRO, 2014, p. 748) , mas $^{5}$ ainda trabalhando a imaginação "exótica" com referências às mitologias, imagens psicodélicas e surreais na decoração externa ou interna (PÉREZ, 2006, p. 182).

A partir dessa massificação midiática, progressivamente os preconceitos se reduziram, fazendo com que o público tatuado fosse ampliado. Hoje as tatuagens não se restringem a determinados grupos ou indivíduos, como exposto por Andrea Pérez:

O novo sujeito da tatuagem parece não ter um rosto definido. É múltiplo, diverso, não tem fronteiras de sexo, percorre as diferentes gerações, transita por todas as classes sociais, pertence a distintos níveis educativos, faz diversas atividades, enfim, não possui, como antigamente, um perfil social determinado. (PÉREZ, 2006, p. 189)

Assim, os valores simbólicos atribuídos por determinados grupos às tatuagens foi remodelado com base na estetização exacerbada dos corpos e os ideais de liberdades individuais, alterando a concepção do corpo em termos de autonomia, agora visto como espaço para expressão da potencialidade criativa individual e forma de exteriorização estética, gerando com isso novos significados, símbolos, histórias e ideias. ${ }^{6}$

Por outro lado, apesar dessa individualização radical, é possível perceber como as relações interpessoais ainda influenciam diretamente as decisões nessas situações, criando os ditos "entraves sociais", dado que as escolhas da localidade dos desenhos no corpo ainda são cautelosas, havendo uma limitação do ambiente externo e seus preconceitos enraizados. Essas circunstâncias revelam o receio de causar rejeições sociais ao expor suas tatuagens ou modificações corporais, visto que algumas pessoas e instituições ainda relacionam essas técnicas à marginalidade e à criminalidade.

A teoria do etiquetamento social parece fornecer uma possível explicação do porquê desses sujeitos sofrerem determinados preconceitos. Essa discriminação remete ao histórico já

\footnotetext{
${ }^{5}$ Muito disso ligado também ao surto do vírus HIV - causador da AIDS - em 1980.

${ }^{6}$ Corroborando com isso, alguns depoimentos coletados por Débora Leitão, em seu trabalho "À flor da pele: estudo antropológico sobre a prática da tatuagem em grupos urbanos" apresentam o aumento de demanda dos estúdios na época do verão e a baixa demanda do inverno, ou seja, o culto ao corpo está diretamente relacionado com a disseminação da tatuagens (LEITÃO; ECKERT, 2004, p. 20).
} 
relatado, sendo sutil, invisível e determinado pela construção, por parte de grupo de sujeitos ou instituições, de padrões. Por conseguinte, surge o afastamento dessas estruturas de padronização, caraterizado como o desvio:

O enfoque do etiquetamento é reflexo de uma sociedade controladora, que é capaz de classificar os indivíduos e condená-los a viverem com marcas do seu passado, a qual seleciona, levando em consideração fatores muitas vezes não ligados diretamente com o ato do desviado, tais como: a classe social, a cor da pele, seus antecedentes criminais, seu 'suposto' grau de arrependimento o que demonstra que o controle social faz com que o enfoque do etiquetamento se perpetue. (BEZERRA, et al., 2016, p. 5.)

Tal descrição, somada à narrativa histórica, evidencia a vivência dos cidadãos, principalmente na realidade brasileira, na qual se relaciona tatuagem aos rótulos de criminalidade, ao ponto da Polícia Militar da Bahia ter levantado dados em uma cartilha de orientação intitulada "Tatuagem: Desvendando Segredos", (SILVA, 2012) com o objetivo de reconhecer pessoas com determinados símbolos e suas infrações cometidas, sendo preocupante as relações nelas realizadas. Por exemplo, segundo a cartilha, as imagens de Jesus Cristo, uma cruz ou de uma mulher indígena são relacionadas com os crimes de homicídio, latrocínio ou roubo; a carpa, o saci pererê ou um duende são relacionados ao tráfico e uso de drogas ilícitas. Nessa linha expõe Andrea Perez:

Desse modo, existe uma tensão latente entre ser "tatuado" e continuar sendo um cidadão produtivo e não excluído, entre querer ser diferente e não ser rejeitado pela sociedade. Uma tensão que subjaz aos preconceitos e aos limites sociais que as pessoas confrontam por meio de sua corporalidade e da busca da individualidade. (PÉREZ, 2006, p.195)

Contudo, o trabalho realizado pela polícia militar baiana é criticada pela carência de cientificidade. De acordo com projeto desenvolvido para entender o universo simbólico da criminalidade (FRANÇA; NETO; ARTUSO, 2016, p. 174), só foi possível fazer alguma dessas confirmações na realidade social, sendo ilógico apresentar essas conclusões dos significados de forma absoluta ${ }^{7}$. Posto isso, resta a hipótese da permanência de preconceitos e limites sociais no que tange ao uso das tatuagens, principalmente na esfera da cultura da polícia militar, instituição que parece categorizar, ou etiquetar, os tatuados como grupo social desviante (DA SILVA, 2019, p. 35). Da mesma forma, as atitudes provenientes da teoria do etiquetamento reiteram a lógica da discriminação para além das agências de controle:

(...) consequências práticas do etiquetamento social para além do sistema penal são o tratamento diferenciado que os etiquetados recebem em seu dia-a-dia. É comum que pessoas atravessem a rua, acelerem o passo, sentem-se afastadas em locais públicos e, ainda mais gravemente, acionem a força policial por pura desconfiança de que aquela pessoa poderia, de alguma maneira, tornar-lhe vítima de um crime. (DA

\footnotetext{
${ }^{7}$ Para compreender mais sobre as incompatibilidades das ilustrações das tatuagens e criminalidade verificar França e Neto, 2016.
} 
SILVA, 2019, p. 40)

Dessa maneira, é possível que seja relacionado formas de exclusões dos setores sociais também na esfera estatal, interferindo na admissibilidade dessas pessoas tatuadas como aptas a exercerem funções no espaço público.

\section{A IMPESSOALIDADE DO ESTADO VERSUS PERSPECTIVAS}

\section{SUBJETIVAS DE SEUS AGENTES: A MARGINALIZAÇÃO DE PESSOAS TATUADAS COMO FATOR DE VIOLÊNCIA SIMBÓLICA}

A existência do Estado Democrático de Direito e o seu princípio republicano têm por função zelar pelo interesse público mediante os poderes conferidos e repartidos pela ordem jurídica (MELLO, 2009, p. 29). Nesse sentido, o Estado como ente personalizado apresenta a estrutura de repartição de funções por meio dos órgãos públicos, formado por agentes - os quais são considerados elementos físicos da Administração - que executam a própria vontade do Estado (CARVALHO FILHO, 2018, p. 67). Ressalta-se que o interesse público é aquele pertinente à sociedade como um todo, que a lei consagra e entrega à conta do Estado como representante do corpo social. (MELLO, 2009, p. 99). Sendo assim, cabe ao ramo do Direito Administrativo realizar esse interesse, disciplinando acerca das funções administrativas e todo corpo que consiste (MELLO, 2009, p. 38), englobando toda a Administração Pública - direta ou indireta - que é constituída de cidadãos com suas respectivas visões de mundo trabalhando em prol da coletividade em estruturas estatais. Esses cidadãos, presentes no quadro do Estado, são definidos como agentes públicos pela lei 8.429/1992, em seu art. $2^{\circ}$ :

\footnotetext{
Reputa-se agente público, para os efeitos desta Lei, todo aquele que exerce, ainda que transitoriamente ou sem remuneração, por eleição, nomeação, designação, contratação ou qualquer forma de investidura ou vínculo, mandato, cargo, emprego ou função nas entidades mencionadas no artigo anterior. (BRASIL, 1992)
}

Tais agentes devem agir sobre postulados fundamentais que inspiram o modo de atuar na Administração Pública, como os princípios da legalidade, moralidade e impessoalidade, expressamente previstos no art. 37 da Constituição de 1988:

Art. 37. A administração pública direta e indireta de qualquer dos Poderes da União, dos Estados, do Distrito Federal e dos Municípios obedecerá aos princípios de legalidade, impessoalidade, moralidade, publicidade e eficiência (...) (BRASIL, 1988, grifo nosso)

Dessa maneira, haveria a limitação da atividade do agente dentro do que se é permitido, diminuindo o desvio de finalidade (CARVALHO FILHO, 2018, p. 75) ou o desvio de poder (DI PIETRO, 2017, p 137).

Ainda nessa perspectiva, o princípio da legalidade afirma que qualquer atividade 
administrativa deve ser autorizada por lei, conferindo legitimidade às atitudes do agente sobre as condições da lei (CARVALHO FILHO, 2018, p. 73). Na mesma lógica, a moralidade permite que o agente atue dentro de preceitos éticos, averiguando critérios de conveniência, oportunidade e justiça em suas ações, reduzindo a possibilidade de condutas ou decisões irrazoáveis, principalmente na esfera de conceitos jurídicos indeterminados (CARVALHO FILHO, 2018, p. 113), pois são os âmbitos em que os agentes mais atuam com discricionariedade, definida como:

(...) é a prerrogativa concedida aos agentes administrativos de elegerem, entre várias condutas possíveis, a que traduz maior conveniência e oportunidade para o interesse público. Em outras palavras, não obstante a discricionariedade constitua prerrogativa da Administração, seu objetivo maior é o atendimento aos interesses da coletividade. (CARVALHO FILHO, 2018, p. 108)

Contudo, sob o viés sociológico, os fundamentos da Administração Pública podem ser refletidos a partir da consideração dessas estruturas como "o conjunto de regras e recursos implicados na reprodução de dinâmicas e práticas sociais.” (AZEVEDO, 2010, p. 27). Nessa linha, o sociólogo francês Pierre Bourdieu analisa o aparato burocrático tomando-o como um sistema de máxima conservação, de modo que a perspectiva estatal culmina por mobilizar determinados conhecimentos e procedimentos como forma de lidar e modelar determinados grupos (BOURDIEU, 1989, p. 175), o que pode ser compreendido como uma prática atravessada por um poder simbólico. Nas palavras do autor:

Os 'sistemas simbólicos', como instrumentos de conhecimento e de comunicação, só
podem exercer um poder estruturante porque são estruturados. O poder Simbólico é
um poder de construção da realidade que tende a estabelecer uma ordem
gnoseológica: o sentido imediato do mundo (e, em particular, do mundo social)
supõe aquilo que Durkheim chama o conformismo lógico, quer dizer, 'uma
concepção homogênea do tempo, do espaço, do número, da causa, que torna
possível a concordância entre as inteligências. (BOURDIEU, 1989, p. 9, grifo nosso)

Como vimos, os concursos públicos expressam uma forma de democratização dos acessos aos cargos e reforçam a preocupação do Estado em não se transmutar em espaço de concessão de privilégios nos moldes do Estado régio. A Constituição apresenta em seu art. 37, incisos I e II:

I - os cargos, empregos e funções públicas são acessíveis aos brasileiros que preencham os requisitos estabelecidos em lei, assim como aos estrangeiros, na forma da lei;

II - a investidura em cargo ou emprego público depende de aprovação prévia em concurso público de provas ou de provas e títulos, de acordo com a natureza e a complexidade do cargo ou emprego, na forma prevista em lei, ressalvadas as nomeações para cargo em comissão declarado em lei de livre nomeação e exoneração. (BRASIL, 1988)

De natureza equitativa, o princípio da impessoalidade, cuja finalidade é nortear o comportamento dos agentes para não prejudicarem ou concederem privilégios (CARVALHO 
FILHO, 2018, p. 75), é presente nos processos de concursos públicos. Além disso, indica que funcionários estatais atuam como manifestantes formais da vontade estatal (DI PIETRO, 2017, p. 138). Portanto, os filtros estruturais das seleções devem ter por fim avaliar as aptidões dos candidatos para determinado cargo. Porém, com isso acabam também moldando um caráter universal de acessibilidade, resgatando as premissas de meritocracia e isonomia (SANTOS, 2014, p. 29), constituintes de um determinado ideal de justiça (SANTOS, 2014, p. 79).

Nesse viés, os órgãos públicos do Estado podem ser compreendidos a partir do conceito de campo construído por Bourdieu. Sendo uma esfera composta por relações e sujeitos na busca por determinar suas preferências como legítimas, produzindo determinada padronização de condutas de acordo com seu interesse, o campo seria sustentado pelas exigências de pessoas ali inseridas: linguagem, postura, símbolos, bens materiais, (BOURDIEU, 1989, p. 69), desenvolvendo suas próprias leis gerais, com certo grau de autonomia parcial (CASTRO, 2018, p. 50) nesse sistema interno no qual o sujeito pertence. Dessa maneira, abrem-se duas possibilidades: ou o indivíduo inserido nesse campo reproduz as condutas formatadas, ou é excluído, sofrendo algum processo de violência para além do plano físico, englobada pela esfera do simbolismo. Este tipo de violência, chamada de violência simbólica, funciona na ordem de um poder oculto e invisível (SOUZA, 2014, p. 140) e opera sob a forma de poder simbólico, que é exercido "com a cumplicidade daqueles que não querem saber que lhe estão sendo sujeitos ou mesmo que o exercem" (BOURDIEU, 1989, p. 8).

Assim,

é enquanto instrumentos estruturados e estruturantes de comunicação e de conhecimento que os sistemas simbólicos cumprem a sua função política de instrumentos de imposição ou de legitimação da dominação, que contribuem para assegurar a dominação de uma classe sobre outra (violência simbólica) dando o reforço da sua própria força às relações de força que as fundamentam e contribuindo assim, segundo a expressão de Weber, para a 'domesticação dos dominados'(BOURDIEU, 1989, p. 11).

Essa forma de dominação tem como resultado o que Bourdieu chamou de imposição de um habitus, definido como a incorporação, por parte dos sujeitos, das estruturas, como um princípio gerador de práticas e incorporador, assumindo a duplicidade de caráter: interiorização da exterioridade e a exteriorização da interioridade" (BOURDIEU, 1989, p. 12). Nessa linha, Maria Vasconcellos ainda explica que "o habitus traduz, dessa forma, estilos de vida, julgamentos políticos, morais, estéticos. Ele é também um meio de ação que permite criar ou desenvolver estratégias individuais ou coletivas." (2004, p. 79). Assim, ainda que 
essas práticas não sejam completamente direcionadas, elas podem ser consideradas em alguma medida influenciadoras nas decisões (CASTRO, 2018, p. 47).

Esses conceitos são de grande valia, uma vez que fornecem instrumentos para se pensar como a vida social passa a ser regrada em prol de determinados interesses, sendo o Direito uma dessas ferramentas para os regramentos do Estado e resolução de conflitos. Pontua-se o campo jurídico, local no qual juristas disputam para determinar o que é o Direito. Para isso, os profissionais estão dispostos a mobilizar os recursos materiais e imateriais conhecimento, títulos - para efetivarem sua visão jurídica sobre determinado assunto de forma decisiva:

\begin{abstract}
O efeito jurídico da regra, ou seja, sua significação real, é determinado na relação de forças específicas entre os profissionais, que tende a corresponder à relação de forças entre as partes envolvidas no conflito. O Direito, nessa perspectiva, é o resultado de uma relação de forças determinada pela estrutura de distribuição do capital entre os agentes, que por sua vez vem determinada pela relação com as diferentes distribuições de outros tipos de capital (econômico, cultural, social etc.).(AZEVEDO, 2010, p. 33)
\end{abstract}

Por conseguinte, o Estado apresenta o monopólio da violência simbólica legítima (BOURDIEU, 1989, p. 236), por ser o poder soberano interno, competindo ao Poder Judiciário - com a judicialização da política - o espaço para a reparação ou impedimento deste tipo de violência, considerando o lugar de vulnerabilidade ocupado (SANTOS, 2014, p. 62) pelos candidatos. Consequentemente, podemos afirmar que os agentes institucionais do regime estatal-jurídico, na teoria de Bourdieu, apresentam elevada concentração de capital simbólico, e concentram a união de todos os outros capitais (AZEVEDO, 2010, p. 29), uma vez que são responsáveis por legitimar valores de maior autoridade reconhecida normativamente dentro de uma nação (BOURDIEU, 1989, p. 199). Assim, como bem coloca Vasconcellos, Bourdieu nos revela como a violência simbólica faz com que os indivíduos vejam como "natural" as representações ou as ideias sociais dominantes desenvolvidas pelas instituições e pelos agentes que as animam e sobre a qual se apoia o exercício da autoridade. (2004, p. 80 - 81). Em outras palavras, é preciso levar em conta que:

Antes, homens e mulheres são antes produtos de uma história individual específica
sobre a qual infere uma série de vetores associados aos distintos espaços de
socialização frequentados pelos indivíduos durantes suas respectivas trajetórias. Não
obstante, os sujeitos também são, além de frutos de suas trajetórias individuais,
resultado de uma dada história coletiva que a estes se impõe por meio das relações
estabelecidas nesses espaços de socialização estruturantes e previamente
estruturados. (CASTRO, 2018, p. 36)

Tais ações individuais não são fruto de meras opções conscientes e/ou interessadas, mas são "influenciadas por todo um conjunto de estruturas e disposições próprias da área 
(historicamente construídas) em que a ação vai ser empreendida, de acordo com a trajetória do indivíduo e seu poder de atuação naquele contexto". Não obstante, elas impactam no campo, promovendo um círculo entre o que leva a ação a ser feita e a ação em si, eliminando a barreira entre objetivismo e subjetivismo". (SANTOS, 2014, p. 19). Por isso, como bem coloca Bourdieu: "para compreendermos o sistema de símbolos é preciso entender os agentes que lutam dentro desses sistemas" (BOURDIEU, 2012, p. 323).

A partir dessas reflexões, é possível compreender a contradição estabelecida entre a exclusão dos candidatos tatuados aos cargos de policiais e a suposta característica do Estado impessoal $^{8}$, que se apresenta como isento de parcialidade, o que nos leva a questionar até que ponto este princípio estaria realmente sendo cumprido, uma vez que os agentes disciplinados e legitimados pelo próprio Estado, permitiriam que elementos subjetivos inferissem no julgamento justo, desviando a atuação do agente da esfera do poder discricionário para a arbitrariedade, desvio ou abuso de poder, cujo processo resulta na configuração da ilegitimidade:

O desvio de poder é conduta mais visível nos atos discricionários. Decorre desse fato a dificuldade na obtenção da prova efetiva do desvio, sobretudo porque a ilegitimidade vem dissimulada sob a aparência da perfeita legalidade (CARVALHO FILHO, 2018, p. 106)

Nesse viés, a discussão promovida no Recurso Extraordinário 898.540 traz importantes elementos para pensarmos essas questões, na medida em que houve a busca por reparação na via judicial nos atos de discriminação pela utilização de tatuagens.

\section{ANÁLISE DO RECURSO EXTRAORDINÁRIO 898.540}

A fim de contextualizar, o Recurso aqui abordado originou-se do julgamento realizado pelo Tribunal de Justiça do Estado de São Paulo, Apelação no 0054636 15.2009.8.26.0053, no mandado de segurança que discutia a constitucionalidade da decisão de exclusão do candidato do Concurso Público para Soldado da Polícia Militar de $2^{\text {a }}$ Classe, que apresentava tatuagem na perna direita. Importante ressaltar que a categoria de policiais militares é enquadrada na categoria mais específica de agentes públicos, sendo servidores públicos militares (CARVALHO FILHO, 2018, p. 703). Dito isso, cabe aqui, portanto, analisar a argumentação proferida pelo Supremo Tribunal Federal.

Inicialmente, a análise antropológica do Ministro Luiz Fux traz à tona a diversificação dos grupos que hoje apresentam tatuagens, considerando não ser razoável as

\footnotetext{
${ }^{8}$ O Estado impessoal é conceito advindo do princípio da impessoalidade, lido sob a premissa de que todos são iguais perante a lei e não pode haver favoritismo, discriminações benéficas. Vide: caput do art. $5^{\circ} \mathrm{e}$ art. 37 , inciso II, ambos da Constituição da República de 1988.
} 
instituições da sociedade reproduzirem esses aspectos de prejulgamento distorcido e segregacionista (BRASIL, 2016, p. 8). No voto do ministro, ele utiliza a perspectiva da autora Andrea Pérez:

\begin{abstract}
Ainda que perdure simbolicamente o sentido de gueto que identificava a tatuagem com os setores marginais, rebeldes ou de classe baixa, já se quebraram na prática esses limites sociais, especialmente desde o seu ingresso no mundo do mercado, quando se tornou uma das opções estético-corporais acessíveis aos distintos públicos. (PÉREZ, 2006, p. 189 -190)
\end{abstract}

Desse modo, esse etiquetamento simbólico perpetuado não está de acordo com as propostas constitucionais, no sentido de haver a materialização de preconceitos pelo setor de pessoas tatuadas, com justificativa insatisfatória, ao acesso de determinados espaços como os postos de trabalho. Assim, o Ministro ainda argumenta a impossibilidade de aplicar a discriminação justificada: "Dar tratamento isonômico às partes significa tratar igualmente os iguais e desigualmente os desiguais, na exata medida de suas desigualdades". (NERY JUNIOR, 1999, p. 42). Ainda nessa linha, "características tais como o sexo, localização espacial, idade, raça, etc., quando não relacionados diretamente com a razão da distinção, não podem justificar a aplicação de norma específica" (BRASIL, 2016, p. 13); ou seja, a distinção promovida pela tatuagem explicitaria o grau de arbitrariedade uma vez que ela própria não afetaria a habilidade para o exercício da profissão de policial, contradizendo então o caput do artigo $5^{\circ}$ da Constituição de 1988 , uma vez que a isonomia estaria sendo infringida por não concretizar a igualdade formal dos cidadãos:

Destarte, toda lei deve respeitar os ditames constitucionais, mormente quando referir-se à tutela ou restrição a direitos fundamentais, o que nos leva à conclusão de que os obstáculos para o acesso a cargos públicos devem estar estritamente relacionados com a natureza e as atribuições das funções a serem desempenhadas. (BRASIL, 2016, p. 6)

Portanto, a Constituição impossibilita a criação de barreiras arbitrárias para a acessibilidade dos cargos, limitando o concurso à possibilidade de criar apenas avaliações de realizações condizentes com as exigências dos cargos, não infringindo os direitos fundamentais (SANTOS, 2014, p. 73). Percebe-se a consonância com outras decisões proferidas pelo Supremo Tribunal Federal no tocante aos concursos, existindo fortes precedentes para a identificação da inconstitucionalidade: Recurso Extraordinário 398.567-1, que considerou ilegal o exame de aptidão física para o cargo de Agente Penitenciário no Estado de Sergipe, pois não havia previsão em lei,, sendo assim a exigência não poderia ser feita somente pelo edital, de modo que o embasamento legal foi considerado imprescindível; o Recurso Extraordinário 558.883-5, que foi contra a exigência de experiência profissional para o investidura em cargo ou emprego público, com a justificativa de que contrariava a 
razoabilidade e as exigências legais; Recurso 593.168, acerca da ilegitimidade da exigência de altura mínima para o concurso para Polícia no Estado de Sergipe, pela inexistência de leis acerca do assunto na época do edital.

Nota-se a importância da existência da previsão legal para os casos de exigências mais específicas dos cargos, não sendo permitido o edital fazer uso de determinada variável exclusiva não prevista em lei, por entender que o princípio da legalidade deve ser respeitado. Logo, a Administração não poderá proibir ou impor comportamento algum a terceiro, salvo se estiver previamente embasada em determinada lei que lhe faculte proibir ou impor alguém o que quer que seja.” (MELLO, 2009, p. 102).

Já na argumentação construída nos pilares do Direito comparado, evidenciou-se que países como os Estados Unidos, Alemanha, Portugal, apresentavam determinadas resistências em relação à utilização de tatuagens por militares e que, em alguns casos, foram sendo desconstruídas paulatinamente de maneiras diferentes. Nos Estados Unidos, a marinha já permite a utilização de forma mais ampla aos seus membros - incontáveis tatuagens e tamanhos diversos -, restringindo apenas as sexistas, ou de cunho racista. Em contraposição, as soluções ditas "mais progressistas" são destaques na Alemanha, visto que a decisão é bem prática, porém limitadora, determinando que as pessoas que apresentam tatuagens devem cobri-las de forma discreta e adequada. Trata-se de decisão bastante parecida com a solução de Portugal, que proíbe as tatuagens visíveis com o uso do uniforme. (BRASIL, 2016, p. 1822)

No Brasil, a decisão proferida indicou semelhança quanto ao fator limitante ao direito à liberdade - salientando que nenhum direito fundamental é absoluto -, uma vez que os candidatos com tatuagens tidas como contrárias aos valores constitucionais e democráticos, ou contra a ordem jurídica, devem ser excluídos, porque não faria sentido um agente do Estado apresentar característica contra as premissas do próprio Estado Democrático de Direito:

O Estado não pode encarar a liberdade de expressão como algo absoluto, porque não o é, mas, também, não está autorizado a impedir que um cidadão exerça uma função pública, mormente quando tiver sido aprovado em um concurso público, pelo fato de ostentar, de forma visível ou não, uma pigmentação definitiva em seu corpo que simbolize alguma ideologia, sentimento, crença ou paixão. Independentemente de ser visível ou do seu tamanho, uma tatuagem não é sinal de inaptidão profissional, apenas podendo inviabilizar o desempenho de um cargo ou emprego público, quando exteriorizar valores excessivamente ofensivos à dignidade dos seres humanos, ao desempenho da função pública pretendida (como na hipótese, verbi gratia, de um candidato ao cargo policial que possua uma tatuagem simbolizando uma facção criminosa ou o desejo de assassinato de policiais), incitação à violência iminente (...) (BRASIL, 2016, p. 25, grifo nosso). 
Ainda nesse raciocínio, o Pacto dos Direitos Civis e Políticos, internalizado no Brasil em 1992, fundamenta tal hipótese de restrição de liberdade em seu artigo 19, determinando que o exercício da liberdade apresenta deveres e responsabilidades:

1. ninguém poderá ser molestado por suas opiniões.

2. Toda pessoa terá direito à liberdade de expressão; esse direito incluirá a liberdade de procurar, receber e difundir informações e ideias de qualquer natureza, independentemente de considerações de fronteiras, verbalmente ou por escrito, em forma impressa ou artística, ou por qualquer outro meio de sua escolha (BRASIL, 1992).

Dessa forma, pode-se garantir o respeito a reputação dos indivíduos ou grupos, de modo que não faria sentido permitir em um Estado Democrático a reprodução do discurso de ódio, seja ele verbal ou não.

No entanto, esse espaço de determinação das representações inconstitucionais ou antirrepublicanas podem ser consideradas muito subjetivas, dependendo do caso concreto. Isto pode gerar a atuação de avaliadores com o desvio de finalidade, ou exclusões (in)justificadas pela aparência de legalidade, impessoalidade e moralidade no discurso construído (CARVALHO FILHO, 2018, p. 106) Conforme já demonstrado, alguns símbolos ou imagens são associadas diretamente à criminalidade, marginalidade, pelas próprias instituições ou seus representantes ${ }^{9}$, sem levar em conta que tais imagens podem estar ligadas a outras experiências de vida dos sujeitos em questão.

Pelo exposto, o Supremo declarou a seguinte tese, com Repercussão Geral: "Editais de concurso público não podem estabelecer restrição a pessoas com tatuagem, salvo situações excepcionais em razão de conteúdo que viole valores constitucionais.” (BRASIL, 2016, p. 41). No entanto, considera-se insuficiente a perspectiva dos "valores constitucionais" pela sua abertura interpretativa e imprecisão jurídica. Resgatando a crítica do campo jurídico, haveria uma própria vinculação do Direito com a reprodução de certos preconceitos, de modo que fatores discriminantes ainda podem estar presentes, produzindo exclusões pela força simbólica ou violenta.

Neste contexto da lógica apresentada, a elasticidade dos textos constitucionais permite certa discricionariedade e liberdade para determinar o que realmente é aceito ou não em termos de tatuagens. O problema central é a grande possibilidade desta discricionaridade

\footnotetext{
${ }^{9}$ Para corroborar com a visão aqui posta cita-se os exemplos de caso concreto do Tribunal de Justiça do Estado de Minas Gerais, em 2018 (após a decisão do Recurso do Supremo Tribunal Federal: Apelação cível $\mathrm{n}^{\circ}$ 1.0024.13.255905-5/002 - 2559055 e a de $n^{\circ} 1.0000 .16 .002580-5 / 002-6133596$ ), que respeitaram a tese de que editais de concurso público não podem estabelecer restrição a pessoas com tatuagem, salvo situações excepcionais em razão de conteúdo que viole valores constitucionais - ressaltando as ponderações colocadas da discricionariedade exacerbada ou arbitrariedade. Chama-se atenção para os casos que ainda estão chegando no Judiciário, mostrando a incerteza jurídica, ainda que haja a interpretação constitucional do Supremo.
} 
se tornar abuso ou desvio de poder pela arbitrariedade. Leva-se a entender que os editais dos concursos podem amparar a discriminação injustificada dos candidatos com tatuagens, uma vez que falta a definição mais exata de valores constitucionais. Como é demonstrado no projeto "As marcas do cárcere", existe a dificuldade nas conclusões sobre tatuagens na realidade da cultura policial: "Na análise geral das marcas das tatuagens, identificamos, porém, um alto índice de tatuagens que revelavam um grave conflito entre a interpretação tradicional da polícia e o significado oferecido pelos próprios apenados sobre elas." (FRANÇA; NETO; ARTUSO, 2016, p. 182).

Assim, os candidatos ficam sujeitos a avaliações de pessoas que podem expressar suas subjetividades por meio dos discursos de seleções nos concursos, com possibilidade de interferência discriminatória neste processo de expressão, alegando a incompatibilidade com a ordem jurídica. Por consequência, permanece ainda um certo grau de insegurança jurídica.

\section{CONSIDERAÇÕES FINAIS}

De antemão, já foi demonstrado como as pigmentações definitivas sofreram um processo de marginalização ainda refletido na contemporaneidade. Nesse viés, o Judiciário brasileiro foi suscitado a se manifestar acerca dos reflexos dessa marginalização nos concursos públicos, ocasião na qual restou vedada a arbitrariedade da exclusão de cidadãos ocuparem esses cargos.

Todavia, parece ainda existir uma abertura em relação à decisão de Repercussão Geral do STF, que se sobressai no seguinte trecho: "salvo situações excepcionais em razão de conteúdo que viole valores constitucionais", uma vez que esses ditos valores apresentam um teor muito abstrato, dada a infinidade de valores implícitos e explícitos dentro da ordem normativa. Para exemplificar, basta pensar como os sujeitos criam significados e narrativas no processo da criação da característica da pigmentação (PEREZ, 2006, p. 201) e estarão submetidos a interpretações, muita das vezes ligadas ao fator da marginalização ou do etiquetamento social dos diferentes cidadãos que compõem o aparato público.

Como bem coloca Bourdieu,

Para ser perfeitamente completo, para explicar os efeitos de racionalidade, seria preciso compreender também por que essas pessoas tinham certo interesse em dar uma forma universal à expressão particular de seus interesses. Por que os juristas e legistas fizeram uma teoria do serviço público, da ordem pública, do Estado como irredutível à dinastia, da República como transcendente aos agentes sociais que o encarnam em determinado momento, ainda que se trate do rei etc.? Que interesse tinham em fazer tudo isso? E qual é a lógica de seu funcionamento, de seu recrutamento, do fato de que tinham privilégios, um capital - o direito romano etc. (BOURDIEU, 2012, p. 324) 
Percebe-se uma limitação excessiva da liberdade das pessoas, no que concerne ao processo de escolha das tatuagens, tendo elas que pensarem nas consequências de serem impedidas por cláusulas de barreiras subjetivas, inserindo-se na concepção da violência simbólica. Nesse sentido, é preciso atentar para o fato de que "o Estado está em estado (se posso dizer) de impor de maneira universal, na escala de certa instância territorial, princípios de visão e de divisão, formas simbólicas, princípios de classificação.” (BOURDIEU, 2012, p. 308), isto é, o Estado produz estruturas estruturantes, universalizantes, dentro de um ambiente completamente plural e aberto, constituindo objetivos do Brasil previstos exemplificadamente no $\operatorname{artigo~} 1^{\text {o }}$ da Constituição de 1988 (FERNANDES, 2017, p. 289).

Destarte, o próprio Estado está sujeito à reprodução de determinados padrões pelos cidadãos, sendo eles possíveis de colidirem com preconceitos enraizados, principalmente em alas estigmatizadas. Como demonstra Filipe Castro em sua tese de doutorado, o campo jurídico da magistratura confere determinada homogeneidade de uma elite conservadoraliberal, (CASTRO, 2018, p. 48 - 49), de modo que esses profissionais, atuando dentro do poder estatal, colocam em prática o seu habitus.

Assim, a maneira de comunicação neutra, impessoal e livre que o Estado apresenta por meio dos editais foi questionada por reproduzir esses aspectos. Para isso, viu-se condutas, instituições e estruturas estruturantes e estruturadas, não permissivas no que concerne a desvios, buscando a homogeneização dos policiais militares.

Deste modo, problematiza-se, retomando a ideia de campo, a utilização do concursos como forma de filtro, uma vez que os candidatos tatuados são excluídos por apresentarem uma característica julgada pelos agentes do campo estatal - Administração Pública direta ou indireta - como incompatível com o cargo de policial militar, sem uma justificativa de discriminação objetiva. Para além disso, visualiza-se a ideia de "valores constitucionais" como um limitante e, ainda, violentador simbólico, dado sua abertura de possível arbitrariedade concedida às bancas julgadoras dos exames.

Tendo em vista essas possibilidades de arbitrariedades nos processos de seleção dos cargos públicos, com permanência de um certo grau de incerteza jurídica diante da questão aqui analisada, conclui-se que se deve buscar maneiras e formas a ir na contracorrente da homogeneização. Uma delas pode ser o reconhecimento do pluralismo ${ }^{10}$ da sociedade brasileira, previstos explicitamente na Constituição Cidadã, e suas diversas formas de

\footnotetext{
${ }^{10}$ Estaria de acordo com os próprios precedentes para reparação da desigualdade e inclusão da diversidade, oriundas de minorias jurídicas: vide Ação Declaratória de Constitucionalidade 41, Supremo Tribunal Federal declara Lei de Cotas Constitucional.
} 
manifestação, incluindo as pessoas tatuadas para o ofício de policiais militares ou em outros cargos públicos.

\section{REFERÊNCIAS BIBLIOGRÁFICAS}

AZEVEDO, Rodrigo Ghiringhelli de. A força do direito e a violência das formas jurídicas. Revista de Sociologia e Política, v. 19, n. 40, p. 27-41, 2011.

BEZERRA, Edson Alves; HAAS, Ronsagela Londera; LEITE, Caio F. G. Teoria do Labelling Approach ou Etiquetamento Social. In: Anais do II Encontro Interdisciplinar da Ajes: Direito e Educação Física. Juína, 2016.

BÍBLIA SAGRADA. Tradução João Ferreira de Almeida. São Paulo: Sociedade Bíblica do Brasil, 2007.

BRASIL. Casa Civil. Decreto $\mathbf{n}^{\mathbf{0}}$ 592: Atos Internacionais. Pacto Internacional sobre Direitos Civis e Políticos. Brasília, 6 de julho de 1992. Disponível em: <http://www.planalto.gov.br/ccivil_03/dec reto/1990-1994/d0592.htm>. Acesso em 19 de mai. 2020.

BRASIL. Constituição da República Federativa do Brasil de 1988. Brasília. Distrito Federal. Disponível em: http://www.planalto.gov.br/ccivil_03/Cons tituicao/ Constituiçao.htm. Acesso em 20 jun. 2019.

BRASIL. Supremo Tribunal Federal. Recurso Extraordinário 898.450. Relator Ministro Luiz BRASIL, Brasília, 17 de agosto de 2016. Brasília: STF, 2016. Disponível em: <http://www.stf.jus.br/portal/cms/verNotic iaDetalhe.asp?idConteudo=323174> . Acesso em 19 de mai. 2020.

BOURDIEU, Pierre. O poder simbólico. Tradução de Fernando Tomaz. Rio de Janeiro: Editora Bertrand Brasil S.A, 1989.
BOURDIEU, Pierre. Sobre o Estado: cursos no Collège de France. Tradução de Rosa Freire d'Aguiar. São Paulo: Editora Schwarcz, 2012.

CARVALHO FILHO, José do Santos. Manual de direito administrativo. 32. Ed. São Paulo: Atlas, 2018.

CASTRO, Felipe Araújo. Genealogia histórica do campo jurídico brasileiro: liberalismo-conservador, autoritarismo e reprodução aristocrática. Tese de Doutorado em Direito, Universidade Federal de Minas Gerais, 2018.

DA SILVA, Luísa Cypriano Moreira. Sistema carcerário brasileiro: uma análise do perfil dos presos a partir das teorias da seletividade penal e do etiquetamento social. Dissertação em Direito, Universidade Federal de Ouro Preto, Ouro Preto, 2019.

DI PIETRO, Maria Sylvia Zanella. Direito administrativo. 30. Ed. São Paulo: Atlas, 2017.

FERNANDES, Bernardo Gonçalves. Direito constitucional. 9 ed. Salvador: JusPODIVM, 2017.

FRANÇA, Leandro Ayres; NETO, Alfredo Steffen; ARTUSO, Alysson Ramos. As marcas do cárcere. Curitiba: IEA, 2016.

LAGROU, Els. Existiria uma arte das sociedades contra o Estado? Revista de Antropologia, p. 747-780, 2011.

LEITÃO, Débora Krischke. Mudança de significado da tatuagem contemporânea. 
Cadernos IHU ideias, v. 2, n. 16, p. 1-24, 2004.

LOMBROSO, Cesare. O homem delinquente. Tradução de Sebastião José Roque. 1. ed. São Paulo: Ícone, 2007.

ECKERT, Cornelia; LEITÃO, Débora Krischke. À flor da pele: estudo antropológico sobre a prática da tatuagem em grupos urbanos. ILUMINURAS, v. 5, n. 10, 2004.

MELLO, Celso Antônio B. D. 26 ed ${ }^{\circ}$. Curso de Direito Administrativo. São Paulo: Malheiros Editores, 2009.

MINAS GERAIS. Tribunal de Justiça de Minas Gerais. Apelação Cível $\mathbf{n}^{\circ}$ 1.0000.16.002580-5/002 -6133596 da $2^{\mathrm{a}}$ Câmara Cível do Tribunal de Justiça do Estado de Minas Gerais. Brasília, DF, 30 de maio de 2018. Disponível em: <https://www5.tjmg.jus.br/jurisprudencia/f ormEspelhoAcordao.do>. Acesso em 17 de mai. 2019.

MINAS GERAIS. Tribunal de Justiça de Minas Gerais. Apelação Cível $\mathbf{n}^{\circ}$ 1.0024.13.255905-5/002 -2559055 da $3^{a}$ Câmara Cível do Tribunal de Justiça do Estado de Minas Gerais. Brasília, DF, 24 de julho de 2018. Disponível em: <https://www5.tjmg.jus.br/jurisprudencia/f ormEspelhoAcordao.do>. Acesso em 20 de mai. 2019.

MORAES, Dênis de. Notas sobre imaginário social e hegemonia cultural. Revista Contracampo, v. 1, n.1, Niterói, julho - dezembro de 1997, p. 93 - 104.

NERY JÚNIOR, Nélson. Princípios do processo civil à luz da Constituição Federal. São Paulo: Revista dos Tribunais, 1999.

OHLWEILER, Leonel Pires. Concursos públicos e restrições ao uso de tatuagens: o poder simbólico do estado e o caso do recurso extraordinário 898.450 julgado pelo STF. Revista Eletrônica Direito e Sociedade-REDES, v. 6, n. 1, p. 349-370, 2018.

PÉREZ, Andrea Lissett. A identidade à flor da pele: etnografia da prática da tatuagem na contemporaneidade. Mana, v. 12, n. 1, p. 179-206, 2006.

PÉREZ, Andrea Lissett. Tatuar e ser tatuado: etnografia da prática contemporânea da tatuagem. Dissertação de Mestrado em Antropologia Social, Universidade Federal de Santa Catarina, Florianópolis, 2003.

RODRIGUEZ, Luciana da Silva; CARRETEIRO, Teresa Cristina Othenio Cordeiro. Olhares sobre o corpo na atualidade: tatuagem, visibilidade e experiência tátil. Psicologia \& sociedade, v. 26, n. 3, p. 746-755, 2014.

SANTOS, Aline Sueli de Salles. Os concursos públicos no campo jurídicoacadêmico brasileiro. Tese de Doutorado em Direito, Universidade de Brasília, Brasília, 2014.

SILVA, Alden José Lazáro da. Tatuagem: Desvendando Segredos. Salvador: Editora Magic Gráficas, 2012.

SOUZA, Rafael Benedito. Formas de pensar a sociedade: o conceito de habitus, campos e violência simbólica em Bourdieu. Ars Historica, n. 7, p. 139-151, 2014.

VASCONCELOS, Maria Drosila. Pierre Bourdieu: a herança sociológica. Educação \& Sociedade, v. 23, n. 78, p. 77-87, 2002.

VILHENA, Junia; ROSA, Carlos Mendes; NOVAES, Joana de Vilhena. Narrando dores: A tatuagem como narrativa. Cadernos de psicanálise (Rio de Janeiro), v. 37, n. 33, p. 129-154, 2015. 


\title{
PUBLIC CONTESTS OF MILITARY POLICE: TATTOOS AS AN UNEXCUSED EXCLUSION'S FACTOR
}

Lorena Martoni de Freitas | Lucas de Souza Prates

How to cite this article: MARTONI DE FREITAS, Lorena; PRATES, Lucas de Souza. Concursos públicos de policiais militares: tatuagem como fator de exclusão injustificada. Revista de Ciências do Estado. Belo Horizonte: v. 5, n. 1, e14946. ISSN: 2525-8036.

\begin{abstract}
Pierre Bourdieu, mainly the symbolic violence, symbolic capital and state-legal field, we sought to analyze the Extraordinary Appeal of number 898.540 of general repercussion, verifying the existence of an unjustified barrier clause which aimed the exclusion of candidates with tattoos in public selections for Military Police. In order to this, the stigma process associated with tattoos has been historically contrasted with the purpose of compare this element of counterculture to the logic of public power, considering the principles of impersonality, legality and efficiency of Administrative Law, seeking to explain how they may not be observed by some agents and institutions of the state apparatus. Thus, it is proposed a critical exercise in relation to the Brazilian State of Law.
\end{abstract}

Keywords: symbolic violence; public contests; state-legal field; administrative law; tattoos. 